\title{
Enduring Deficits in Sustained Visual Attention during Withdrawal of Intravenous Methylenedioxymethamphetamine Self-Administration in Rats: Results from a Comparative Study with $d$-Amphetamine and Methamphetamine
}

\author{
Jeffrey W Dalley*,', Kristjan Lääne', David EH Theobald', Yolanda Peña', Charlotte C Bruce', \\ Anthony C Huszar', Michael Wojcieszek', Barry J Everitt' and Trevor W Robbins' \\ 'Department of Experimental Psychology and Behavioral and Clinical Neuroscience Institute, University of Cambridge, Cambridge, UK
}

\begin{abstract}
Although amphetamine-derived stimulants are widely associated with neurotoxicity, it is poorly understood whether extended exposure to such drugs produces lasting effects on neurocognitive function. This study investigates whether chronically self-administered $d$ amphetamine, methamphetamine (MA), or methylenedioxymethamphetamine (MDMA) leads to residual deficits in a rodent test of sustained visual attention and impulsivity. Rats were trained on a five-choice serial reaction time task and subsequently trained to selfadminister $d$-amphetamine, MA, or MDMA (all $50 \mu \mathrm{g} /$ infusion), intravenously, for 3 weeks. Effects on performance were evaluated $24 \mathrm{~h}$ after drug discontinuation and for several weeks thereafter, including various challenge sessions to increase the attentional demands of the task. The results indicate divergent patterns of self-administration among the three drugs tested with increasing rates of intake evident in rats self-administering amphetamine, but not MA, and widely fluctuating rates in the MDMA group. Withdrawal of MA resulted in severe behavioral disturbances, with significant effects on accuracy, omissions, response latency, and impulsivity that lasted up to 2 weeks in some cases. Amphetamine and MDMA withdrawal were associated with similar, but shorter-lasting effects on performance. However, when challenged with a high event rate session 6 weeks after drug discontinuation, rats previously exposed to MDMA continued to show deficits in the accuracy and speed of responding. These findings show that amphetamine-derived stimulants have both short- and longterm consequences for psychomotor functioning. The demonstration of residual deficits in rats chronically exposed to MDMA raises some concern about the potential harm caused by this drug in human ecstasy users.

Neuropsychopharmacology (2007) 32, I 195- 1206. doi:I0.1038/sj.npp. I 30 I220; published online II October 2006
\end{abstract}

Keywords: stimulants; five-choice serial reaction time task; cognition; drug addiction; ecstasy

\section{INTRODUCTION}

There has been a recent sharp rise in amphetamine abuse in humans and renewed efforts to determine whether psychostimulant drugs of abuse irretrievably harm the brain (McCann et al, 1998a; Ernst et al, 2000; Nordahl et al, 2003; Thompson et al, 2004; McCann and Ricaurte, 2004). Studies in human drug abusers support the existence of specific psychological deficits during acute drug withdrawal (Simon et al, 2000; Sim et al, 2002; Kalechstein et al, 2003), but there

\footnotetext{
* Correspondence: Dr JW Dalley, Department of Experimental Psychology and Behavioral and Clinical Neuroscience Institute, University of Cambridge, Downing Street, Cambridge CB2 3EB, UK, Tel: + 441223765 29|, Fax: + 441223333564 ,

E-mail: jwd20@cam.ac.uk

Received I June 2006; revised 21 August 2006; accepted 28 August 2006

Online publication: 8 September 2006 at http://www.acnp.org/ citations/Npp090806060367/default.pdf
}

is a lack of reliable data on the long-term neurocognitive profile of abstinent stimulant abusers. Even more difficult is that drug abuse may coexist with other neuropathologies that may, in some circumstances, predate drug-taking behavior (Khantzian, 1985; Levin and Kleber, 1995; Sim et al, 2002). For these reasons, studies using animal models are especially important to establish the long-term effects on cognition of amphetamine and other drugs of abuse.

Substantial research in rodents and non-human primates indicates that amphetamine, methamphetamine (MA) and methylenedioxymethamphetamine (MDMA) are potentially toxic to the brain dopaminergic and serotonergic systems (Seiden et al, 1976; Lorez, 1981; Ricaurte et al, 1992; Woolverton et al, 1989; Melega et al, 1997; Semple et al, 1999; McCann et al, 1998b; Ernst et al, 2000; Cornish et al, 2003; Segal et al, 2005). Consistent with these findings postmortem indices of striatal dopamine (DA) nerve terminal function, including levels of DA, tyrosine hydroxylase, and DA transporter, are reduced in recently deceased chronic 
MA users (Wilson et al, 1996). Structural and metabolic changes in the brain are also a reported consequence of chronic stimulant abuse that is evidently persistent in some cases (Ernst et al, 2000; Robinson and Kolb, 2004; Thompson et al, 2004; Wang et al, 2004; London et al, 2005).

However, increasingly, there have been reports of functional recovery following protracted abstinence from drugs such as MA, for example, especially of the striatal DA systems (Melega et al, 1997; Harvey et al, 2000; Volkow et al, 2001; Stefanski et al, 2002; but see Segal et al, 2005). Indeed, a recent brain imaging study in detoxified human MA addicts found that DA transporter levels in the striatum recover following protracted drug abstinence (Volkow et al, 2001). However, other deficits such as decreased cortical glucose metabolism persisted for periods up to 17 months (Wang et al, 2004), suggesting that chronic MA use may cause intractable cognitive impairment. To date, however, little is known about the nature, severity, and time course of such deficits in animals. Moreover, it is not known whether the approach of administering high, noncontingent doses of stimulants to animals, is relevant to the profile of cognitive impairment in animals trained to self-administer these same compounds.

Our aim in this study was to elucidate the effects of extended intravenous (i.v.) self-administration of $d$-amphetamine, MA, and MDMA on pretrained performance of a five-choice serial reaction time (5-CSRT) task, an automated operant procedure for assessing visual attention and impulsivity in rodents (Robbins, 2002). Performance on this task depends on the functional integrity of many of the same limbic cortical-striatal brain structures affected by chronic drug abuse, including dorsal and ventral prefrontal cortex, orbitofrontal cortex, and the nucleus accumbens (Volkow et al, 1993; Robbins, 2002; Chudasama et al, 2003; Hester and Garavan, 2004; Thompson et al, 2004; Wang et al, 2004). In addition, lesions of the primary neurochemical targets of stimulant drugs, namely the DA and serotonin (5-HT) systems, produce distinct deficits on the 5-CSRT task. Specifically, mesostriatal DA loss primarily affects the speed and vigor of responding, whereas selective 5-HT depletion impairs inhibitory response control leading to increased impulsivity (Harrison et al, 1999; Robbins, 2002; Winstanley et al, 2004). This study tests for the occurrence of residual deficits in performance on the 5-CSRT task following prolonged withdrawal from chronically selfadministered amphetamine, MA, or MDMA. In particular, we have tested the hypothesis that chronic drug exposure leads to deficits in impulse control (Jentsch and Taylor, 1999), especially in the case of MDMA, a popular recreational drug widely recognized for its toxicity to the brain 5-HT systems (Ricaurte et al, 1992; McCann et al, 1998a; Fantegrossi et al, 2004).

\section{MATERIALS AND METHODS}

\section{Subjects}

The subjects were 33 male Lister Hooded rats (Charles River, UK), weighing $350-410 \mathrm{~g}$ at the time of i.v. surgery. Following surgery, animals were housed individually in a temperature- and humidity-controlled holding room under a $12 \mathrm{~h}$ light/dark cycle (lights off at 0730 hours). Animals were placed on a food-restricted diet $(14 \mathrm{~g}$ laboratory chow/day, Purina, UK) to maintain body weight at roughly $85-90 \%$ of free-feeding weight during behavioral testing. Animals' weights were recorded every week and food provision adjusted accordingly to ensure uniform body weights throughout the study. All procedures complied with the requirements of the UK Animals (Scientific Procedures) Act of 1986 (Project number 80/1767).

\section{Behavioral Training on the 5-CSRT Task}

The apparatus consisted of eight nine-hole chambers $(25 \times 25 \times 25 \mathrm{~cm})$ each housed within a ventilated wooden sound-attenuating box. The rear wall of the chamber was curved with nine contiguous $2.5 \times 2.5 \mathrm{~cm}$ apertures, $4 \mathrm{~cm}$ deep and set $2 \mathrm{~cm}$ above a wire grid floor. A metal insert blocked every alternate hole (ie, holes $1,3,5,7$, and 9 were left open). A photocell beam was located at the entrance of each aperture to detect nose-poke responses. A $3 \mathrm{~W}$ stimulus light was located at the rear of each of the five apertures. On the front of the chamber, a magazine connected to a food dispenser allowed the automatic delivery of $45 \mathrm{mg}$ food pellets (Noyes dustless pellets, Research Diets, UK). Subjects gained access to the food magazine by pushing a hinged Perspex panel monitored by a microswitch. A PC using WhiskerServer software (version 2.8) and FiveChoice client (version 2.6) controlled the apparatus.

Subjects were trained on the 5-CSRT task over 45 daily sessions (5-6 sessions/week). Each session consisted of 100 discrete trials and lasted approximately $30 \mathrm{~min}$. Trials were initiated by animals entering the food magazine. After an intertrial interval (ITI) of $5 \mathrm{~s}$ had elapsed, a brief visual stimulus of duration $0.5 \mathrm{~s}$ was presented in a single aperture, the location of which varied on a trial-by-trial basis. Rats were rewarded with a single food pellet if they correctly located the position of the target stimulus with a nose-poke response. A failure to respond within $5 \mathrm{~s}$ of the target presentation (deemed an 'omission') resulted in a time-out of $5 \mathrm{~s}$ where the house-light and tray-light were extinguished for $5 \mathrm{~s}$ and no food was made available. Responses made before the target stimulus or in an adjacent hole were deemed 'premature' and 'incorrect', respectively. Each of these trial types also resulted in a $5 \mathrm{~s}$ time-out. Omissions were expressed as a percentage of correct + incorrect + omission trials (maximum 100\%). Premature or impulsive responses were expressed as a percentage of correct + incorrect + omission + premature trials. A premature response was considered an incomplete trial and had the effect of resetting the previous trial. Response accuracy was defined as the proportion of correct responses to incorrect responses expressed as a percentage. Two measures of the speed of responding were used. The first was latency to respond correctly, defined as the time between the onset of the target stimulus and the response. The second measure was latency to collect food reward from the magazine, defined as the time between the correct response and the first entry into the magazine. Animals were considered to have acquired the basic task when their accuracy of responding was at least $80 \%$ and omissions were stable and less than $20 \%$. 


\section{I.V. Catheterization and 5-CSRT Task Baseline Assessment}

Subjects were anesthetized with ketamine (Ketalar, $100 \mathrm{mg} /$ kg, intraperitoneally (i.p.); Vet Drug, Bury St Edmunds, UK) and xylazine (Rompun, $12 \mathrm{mg} / \mathrm{kg}$, i.p.; Vet Drug) and implanted with an i.v. catheter (CamCaths, Cambridge, UK) that exited dorsally between the scapulae as described previously (Caine et al, 1992). Catheters were maintained by flushing once weekly with $0.2-0.4 \mathrm{ml}$ saline $(0.9 \%$ sterile saline; CP Pharmaceuticals Ltd, Wrexham, UK). Subjects were given at least 7 days to recover from surgery before being re-tested on the 5-CSRTT over 7 daily sessions. The ITI was increased to $7 \mathrm{~s}$ on day 3 to increase the frequency of impulsive responding (Dalley et al, 2005a).

\section{I.V. Drug Self-Administration}

Detailed descriptions of the self-administration procedure can be found elsewhere (Dalley et al, 2005b). Briefly, the self-administration chambers $(24 \times 20 \times 22 \mathrm{~cm}$; Med Associates, UK) were equipped with two levers located $10 \mathrm{~cm}$ apart and $5 \mathrm{~cm}$ above the grid floor. One was designated the 'active' lever, responses on which resulted in drug delivery and the illumination of a white stimulus light $(3 \mathrm{~W}, 24 \mathrm{~V})$ positioned directly above the lever. Responses on the second 'inactive' lever were recorded but had no consequences. A software-operated pump delivered the drug infusions and a PC using WhiskerServer software (version 2.8) and a SecondOrder client (version 3.4) controlled the self-administration apparatus (Cardinal and Aitken, 2001).

Subjects were divided into four groups destined to receive either yoked infusions of sterile saline $(n=9)$, self-administered $d$-amphetamine $\quad(n=8), \quad(+)$-MA $(n=10)$, or $( \pm)$-MDMA $(n=6)$. Self-administration was conducted over 21 consecutive days under a fixed ratio- 1 schedule of reinforcement. Each infusion delivered $50 \mu \mathrm{g}$ of the free drug base in $0.1 \mathrm{ml}$ saline. The selection of doses for $d$-amphetamine, MA, and MDMA was based on recent studies showing these to reliably support i.v. self-administration in rats (Stefanski et al, 2002; Cornish et al, 2003; Dalley et al, 2005a; Shepard et al, 2006; Kitamura et al, 2006). It was assumed that rats would titrate drug intake to achieve relatively optimal levels of drug in the plasma. No attempt was made therefore to correct the unit dose of each drug based on relative differences in biopotency, elimination half-live or molecular weight. On the first 5 days, access was limited to 25 infusions a day. On days 6-21, access to each drug was increased by increasing the session duration to $8 \mathrm{~h}$ and the maximum number of infusions potentially achievable to 75 .

\section{Re-Testing on the 5-CSRT Task during Extended Drug Withdrawal}

Subjects were re-tested on the 5-CSRT task $24 \mathrm{~h}$ after the last self-administration session. Attentional performance was assessed for 24 consecutive daily sessions, each $30 \mathrm{~min}$ in duration and consisting of 100 trials. The stimulus duration and ITI was 0.5 and $5 \mathrm{~s}$, respectively. On days 5,12 , and 19, the ITI was increased to $7 \mathrm{~s}$ and the session duration increased to $60 \mathrm{~min}$. These challenge sessions were used to encourage premature responding and so avoid any potential floor effects on this form of impulsivity (see Dalley et al, 2002).

Following this test phase, rats were left in their home cage for 6 weeks with free access to water and a restricted food diet $(18 \mathrm{~g} / \mathrm{rat} /$ day). They were then tested under different challenge conditions, specifically to increase the demand for attentional processing and inhibitory response control. Challenge sessions consisted of (in the following sequence) a reduced stimulus duration $(0.125 \mathrm{~s})$, variable ITI, white noise distractor, and a high event rate, which were each separated by 2 days of baseline testing (stimulus duration and ITI, 0.5 and $5 \mathrm{~s}$, respectively). The variable ITI session consisted of four discrete ITIs $(2,4,6$, and $8 \mathrm{~s})$, with trials presented uniformly across each ITI in a pseudorandom order. White noise ( $0.5 \mathrm{~s}$ in duration) was presented during the ITI $4.5,3.5,2.0$, or $0.5 \mathrm{~s}$ before the onset of the visual target. The high event rate session consisted of a short fixed ITI of $2 \mathrm{~s}$ and was terminated after 200 trials.

\section{Drugs}

d-Amphetamine sulfate, $(+)$-MA hydrochloride, and $( \pm)$ MDMA hydrochloride were purchased from Sigma-Aldrich (UK) and dissolved in sterile saline (CP Pharmaceuticals, Wrexham, UK). Doses were determined from the combined weight of the free base and salt.

\section{Statistical Analyses}

All analyses were conducted using repeated measures analysis of variance (ANOVA; SPSS type III sum-of-squares method, version 12, SPSS Inc., Chicago, IL). Significant deviations from the requirement of homogeneity of variance were assessed by the Mauchly Sphericity test and corrected using the Huynh-Feldt (HF) epsilon ( $\varepsilon$ ) to adjust degrees of freedom as recommended by Keppel (1991). All tests of significance, including tests of sphericity of the covariance matrix, were performed at $\alpha=0.05$.

In a previous study, withdrawal from 5-day amphetamine self-administration resulted in increased omissions, which while high in magnitude $(\sim 50 \%)$, nevertheless permitted attentional accuracy to be reliably computed (Dalley et al, 2005a). In this study, however, withdrawal from $d$-amphetamine and MA self-administration greatly increased omissions $(>80 \%)$ to the point that attentional accuracy provided a less robust measure of performance. Hence, in this study, the number of correct responses indexed the spatial accuracy of performance. Behavioral variables on the 5-CSRT task were first analyzed to ensure uniform matching of baseline behavioral data between future control and drug self-administering animals. Accuracy data were transformed using the formula $x^{\prime}=2 \arcsin [\sqrt{ } x]$ before ANOVA. Performance effects during stimulant withdrawal were computed across six bins, each consisting of four consecutive daily sessions described in the form $A_{2} \times\left(B_{4} \times C_{6} \times S\right)$, where $A$ is the between-subjects factor group with two levels (saline, drug), $B$ is the within-subjects factor session with four levels (four consecutive daily test sessions), $C$ is the within-subjects factor bin (six levels) and $S$ represents subjects. Effects on performance of the various challenge sessions were 
computed using two-way ANOVA with factors group (two levels) and manipulation (four levels) and independent $t$-tests where appropriate.

\section{RESULTS}

\section{Acquisition and Rate of i.v. Drug Self-Administration}

As shown in Figure 1, subjects readily acquired i.v. $d$-amphetamine, MA, and MDMA self-administration. However, although active lever responses were significantly greater than inactive lever responses for all groups (amphetamine: $\quad \mathrm{F}_{1,7}=556 ; \quad p<0.01 ; \quad \mathrm{MA}: \quad \mathrm{F}_{1,9}=1203$; $p<0.01$; MDMA: $\mathrm{F}_{1,5}=11.46 ; p=0.02$ ), significant variations were encountered in the rate of self-administration for each of these drugs. Thus, rates increased progressively for $d$-amphetamine up to session $12\left(\mathrm{~F}_{20,140}=2.49 ; p=0.01\right)$, but not for MA $\left(\mathrm{F}_{20,180}=1.68 ; \operatorname{HF}(\varepsilon)=0.34 ; p=0.21\right)$, whereas for MDMA, the rate of self-administration showed appreciable variation, with especially high rates during the first 5 days of exposure and lower rates thereafter $\left(\mathrm{F}_{20100}=10.54 ; p<0.01\right)$. Notably, following an initial decline in active lever responding from day 6 to day 11 , responding on the drug lever increased with continued MDMA exposure, almost to levels approaching those of $d$-amphetamine and MA.

\section{Behavioral Consequences of $d$-Amphetamine, MA, and MDMA Withdrawal}

Before the withdrawal phase of the experiment, animals destined to receive $d$-amphetamine, MA, or MDMA were evenly matched for baseline performance compared with future control subjects destined for yoked infusions of saline (all F-values $<1$, NS).

Figure 2 summarizes the effects on 5-CSRT task performance of amphetamine withdrawal. The main effects were a reduction in the number of correct responses, an increase in omissions, and a general slowing of responding to the visual targets; however, there were no significant effects on impulsivity. These deficits were apparent for at least 4 days with no obvious long-term effects during protracted withdrawal. Thus, ANOVA revealed significant bin $\times$ session $\times$ group interactions for correct responses $\left(\mathrm{F}_{15,225}=5.59 ; \quad p<0.01\right), \quad$ omissions $\quad\left(\mathrm{F}_{15,225}=10.32\right.$; $p<0.01)$, and correct response latencies $\left(\mathrm{F}_{15,225}=5.20\right.$; $p<0.01$ ), and significant main effects of group (corrects: $\mathrm{F}_{1,15}=173 ; \quad p<0.01 ;$ omissions: $\mathrm{F}_{1,15}=129.6 ; \quad p<0.01$, correct latencies: $\left.F_{1,15}=48.9 ; p<0.01\right)$ and significant group $\times$ session interactions for all three behavioral variables during the first 4 days of amphetamine withdrawal only (ie, bin 1).

Withdrawal from 21-day i.v. MA self-administration resulted in more severe disturbances in attentional
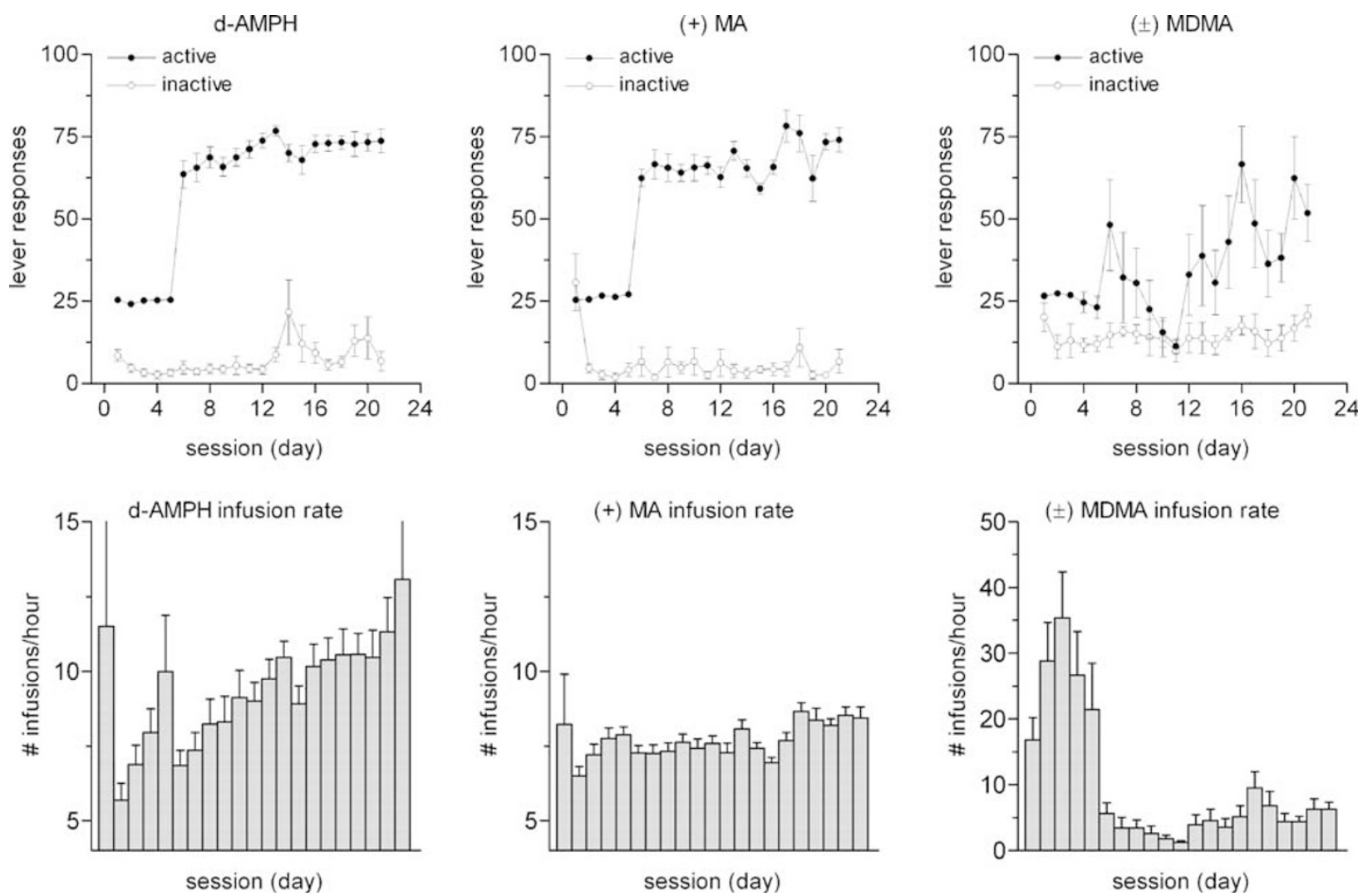

Figure I Number of active and inactive lever press responses during $d$-amphetamine, MA, and MDMA self-administration maintained under a fixed ratio (FRI) schedule of reinforcement (upper graphs). Access to drug was restricted on the first 5 days to 25 infusions. On days 6-2I, access was increased to 75 infusions. Session limits of 5 and $8 \mathrm{~h}$ were imposed for the acquisition and maintenance stages, respectively. The lower graphs show the mean rate of $\mathrm{d}$ amphetamine, MA, and MDMA self-administration (number of infusions/h). Error bars represent \pm I SEM. 

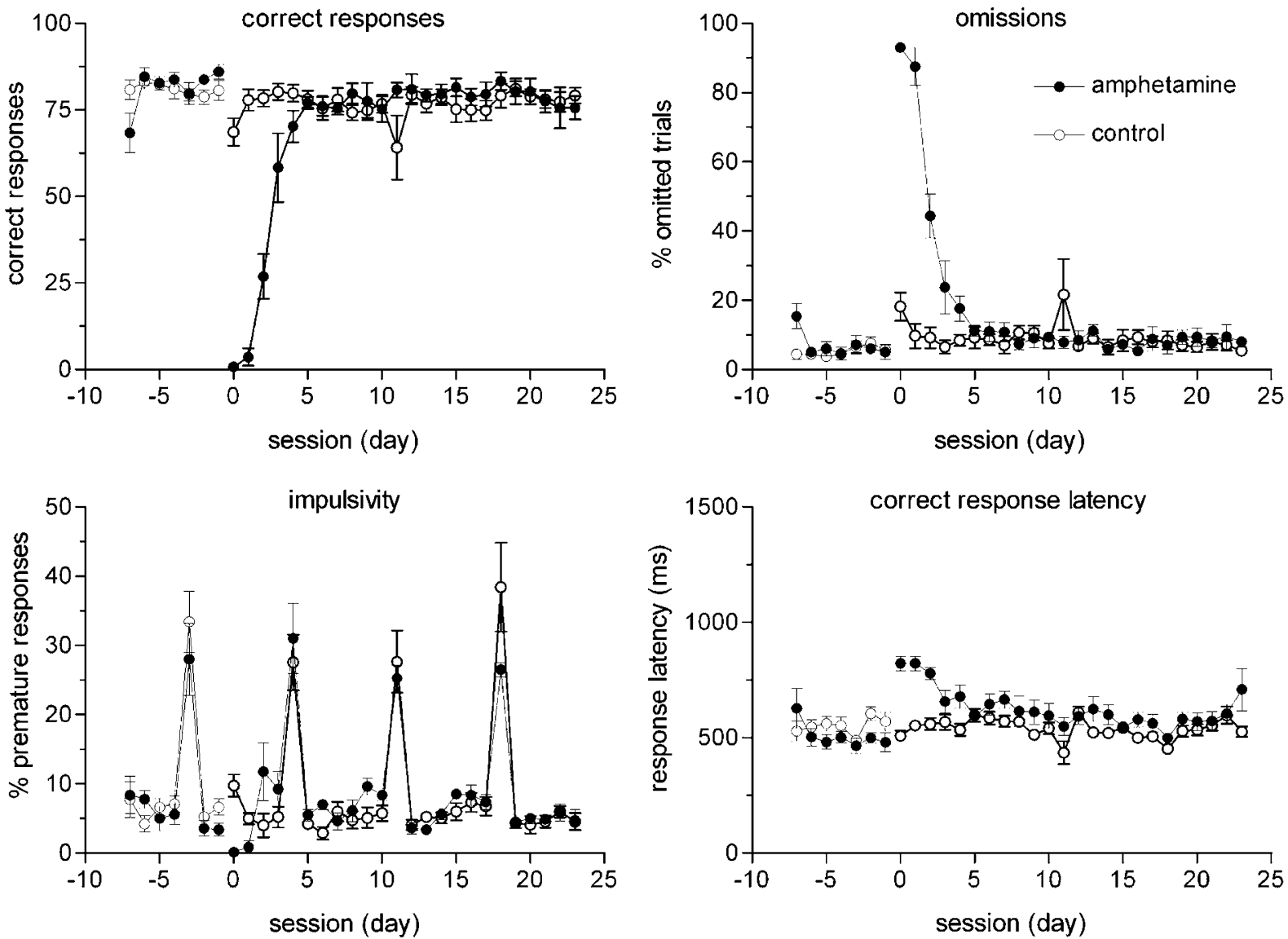

Figure 2 Transitory impairments in attentional performance in rats withdrawn from extended access to i.v. $d$-amphetamine self-administration. Shown are mean $( \pm$ I SEM) correct responses, percentage omissions, percentage premature responses, and mean response latencies in active self-administering animals (closed symbols) and control subjects administered passive infusions of $0.9 \%$ saline (open symbols). Before i.v. self-administration, baseline performance on the 5-CSRT task was determined for 7 consecutive days. Postdrug performance was assessed $24 \mathrm{~h}$ after amphetamine discontinuation (shown as 'day 0').

performance that lasted up to 2 weeks in some animals (see Figure 3). In addition, and unlike amphetamine, MA withdrawal was associated with a significant increase in impulsive responding. Thus, our analysis revealed significant bin $\times$ session $\times$ group interactions for correct $\left(\mathrm{F}_{15,255}=2.89 ; p<0.01\right)$ and premature $\left(\mathrm{F}_{15,255}=2.90\right.$; $p=0.005)$ responses, and significant bin $\times$ group interactions for omissions $\left(\mathrm{F}_{5,85}=46.6 ; p<0.01\right)$ and correct response latencies $\left(\mathrm{F}_{5,85}=9.93 ; p<0.01\right)$. Correct responding significantly decreased relative to controls during bin 1 (corrects: $\left.\mathrm{F}_{1,17}=519 ; p<0.01\right)$ and bin $2\left(\mathrm{~F}_{1,17}=13.77\right.$; $p<0.01$ ), but not during subsequent bins. Likewise, omissions decreased significantly during this period (bin $1: \mathrm{F}_{1,17}=123.4 ; p<0.01 ;$ bin $2: \mathrm{F}_{1,17}=8.05 ; p=0.01$ ), whereas correct response latencies increased, but only during bin $1\left(\mathrm{~F}_{1,17}=13.4 ; p<0.01\right)$. Finally, there was a delayed increase in premature responding that reached statistical significance during bin 3 relative to controls (ie, withdrawal days 9-12; $\mathrm{F}_{1,17}=8.29 ; p=0.01$ ).

MDMA withdrawal was associated with qualitatively similar effects on performance, although of the three drugs tested, this compound produced the least disruptive effects during this phase of baseline testing (see Figure 4). During the acute period of withdrawal (ie, bin 1), correct responses significantly decreased $\left(F_{1,13}=7.69 ; p=0.016\right)$, but there were no significant effects on omissions or correct response latencies. By contrast, MDMA withdrawal was associated with an overall increase in premature responding (group: $\left.\mathrm{F}_{1,13}=7.71 ; p=0.016\right)$, which was significantly compared to controls during bin 2 (ie, withdrawal days $5-8, \mathrm{~F}_{1,13}=7.02$; $p=0.02$ ).

The effects of discontinuing i.v. $d$-amphetamine, MA, and MDMA self-administration on magazine latencies on the 5CSRT task are shown in Figure 5. Rats destined to receive either compound were evenly matched for baseline latencies compared with future control rats (all F-values $<1$, NS). During the acute withdrawal period, magazine latencies were significantly slower in rats withdrawn from $d$ amphetamine (bin 1: $\mathrm{F}_{1,15}=8.83 ; p=0.01$ ), MA (bin 1: $\mathrm{F}_{1,17}=7.41 ; p=0.014$ ), and MDMA (bin 1: $\mathrm{F}_{1,13}=11.60$; $p=0.005)$. However, this was a transient phenomenon with latencies to collect food reward recovering to control levels by approximately the fourth day of withdrawal in the $d$-amphetamine and MA groups. Latencies in the MDMA group showed a slower pattern of recovery (bin 2: $\mathrm{F}_{1,13}=4.96 ; p=0.044 ;$ bin $3: \mathrm{F}<1$, NS).

\section{Attentional Challenges during Protracted Drug Withdrawal}

Following baseline testing, animals were maintained in a drug-free state for a further 6 weeks and then re-tested 

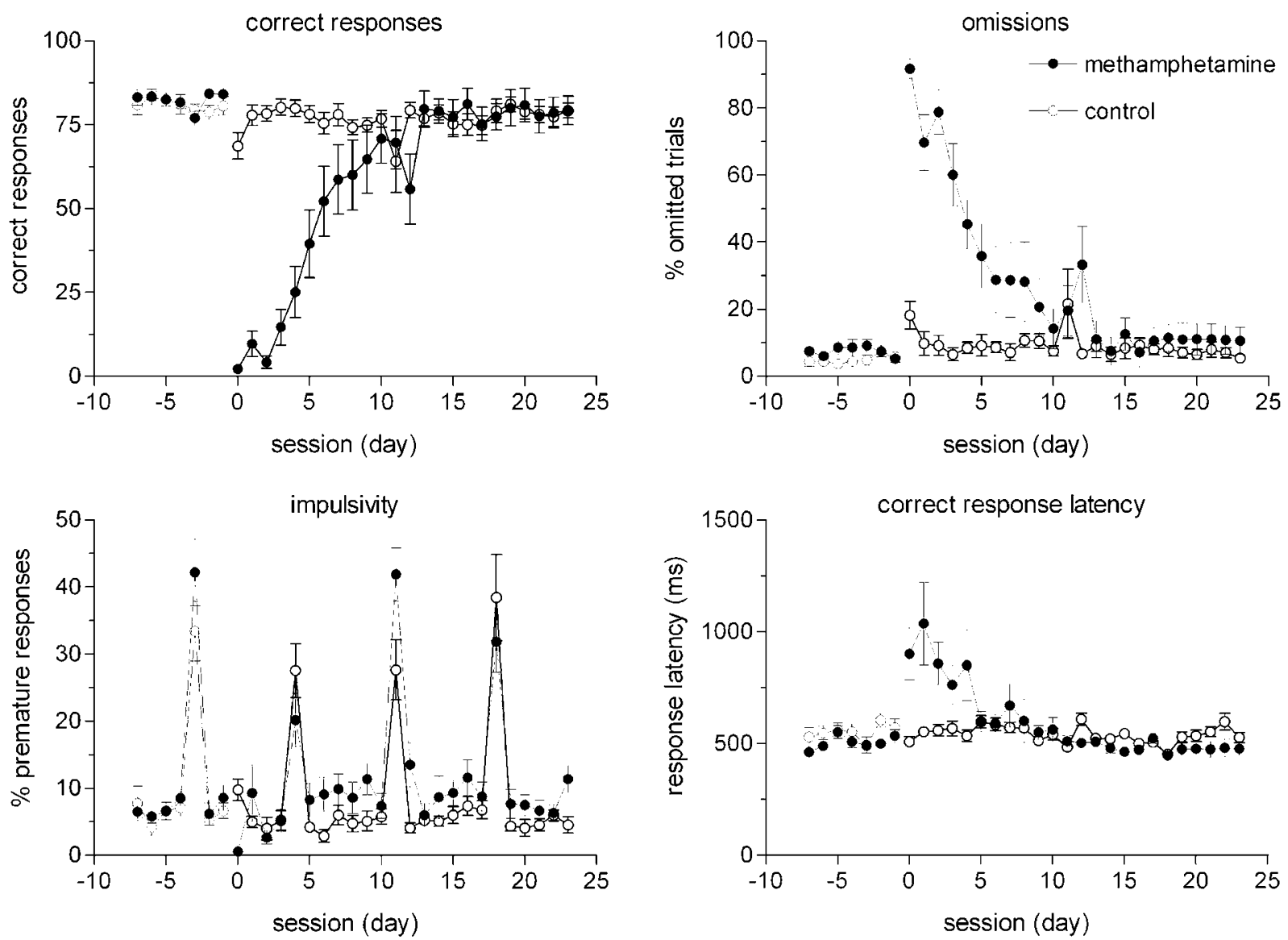

Figure 3 Long-lasting deficits in visual attentional performance in rats withdrawn from i.v. (+)-MA self-administration. Shown are mean ( \pm I SEM) correct responses, percentage omissions, percentage premature responses, and mean response latencies in active self-administering animals (closed symbols) and control subjects administered passive infusions of $0.9 \%$ saline (open symbols). Animals were tested on the 5-CSRT task $24 \mathrm{~h}$ after withdrawal of i.v. MA self-administration (shown as 'day 0'). Aside from obvious effects on correct responses, omissions, and response latency, MA withdrawal was also associated with a significant increase in impulsivity on the 5-CSRT task (see text for details).

under different conditions to tax various aspects of attentional performance. The findings are shown in Figure 6. MDMA-exposed rats showed a general deterioration in performance, mainly but not exclusively during the high event rate session when the target stimuli were presented frequently over many trials. Specifically, MDMA rats showed reduced accuracy (group: $\mathrm{F}_{1,13}=5.33$; $p=0.038$; pair-wise $t$-test; $p=0.033$ ), increased omissions (group $\times$ manipulation: $\mathrm{F}_{3,39}=6.75 ; p=0.006 ;$ pair-wise $t$-test; $p=0.022)$, slower correct response latencies (group $\times$ manipulation: $\mathrm{F}_{3,39}=2.97 ; p=0.043$; pair-wise $t$-test; $p=0.031$ ), and increased magazine latencies (groupmanipulation: $\quad \mathrm{F}_{3,39}=4.31 ; \quad p=0.01 ;$ pair-wise $t$-test; $p<0.01)$. The MDMA group also showed slower response latencies $(p=0.049)$ and fewer premature responses (group $\times$ manipulation: $\mathrm{F}_{3,39}=4.97 ; \quad p=0.005$; pair-wise $t$-test; $p=0.024)$ during the variable ITI session and fewer premature responses $(p=0.008)$ and increased magazine latencies $(p=0.006)$ during the white noise distraction session. Magazine latencies also increased significantly in the MA group during both the white noise distraction session $(p=0.02)$ and the high event rate session $(p=0.03)$.

\section{DISCUSSION}

This investigation was motivated by the paucity of data on the consequences of stimulant drug self-administration on defined cognitive and behavioral functions assessed before, and following, drug self-administration. The 5-CSRT task provides an automated assessment of visuospatial attention and impulsivity in rodents and depends in particular on the functional integrity of the prefrontal cortex and striatum, as well as the cortically projecting DA, NA, ACh, and 5-HT systems of the brain (Robbins, 2002). Previous work has shown that diverse drugs of abuse, including self-administered heroin, cocaine, and $d$-amphetamine, similarly impair attentional performance on this task and that these deficits, in the main, recover fully with protracted abstinence (Dalley et al, 2005a,b). This study extends these findings by showing that MA and MDMA also disrupt performance during the acute withdrawal period, with especially longlasting deficits induced by prior MA exposure. The results also show that impulsivity, as defined operationally by increased levels of responding before the onset of the target stimulus, is one short-term consequence of MA and MDMA withdrawal, not seen with $d$-amphetamine, cocaine, or 

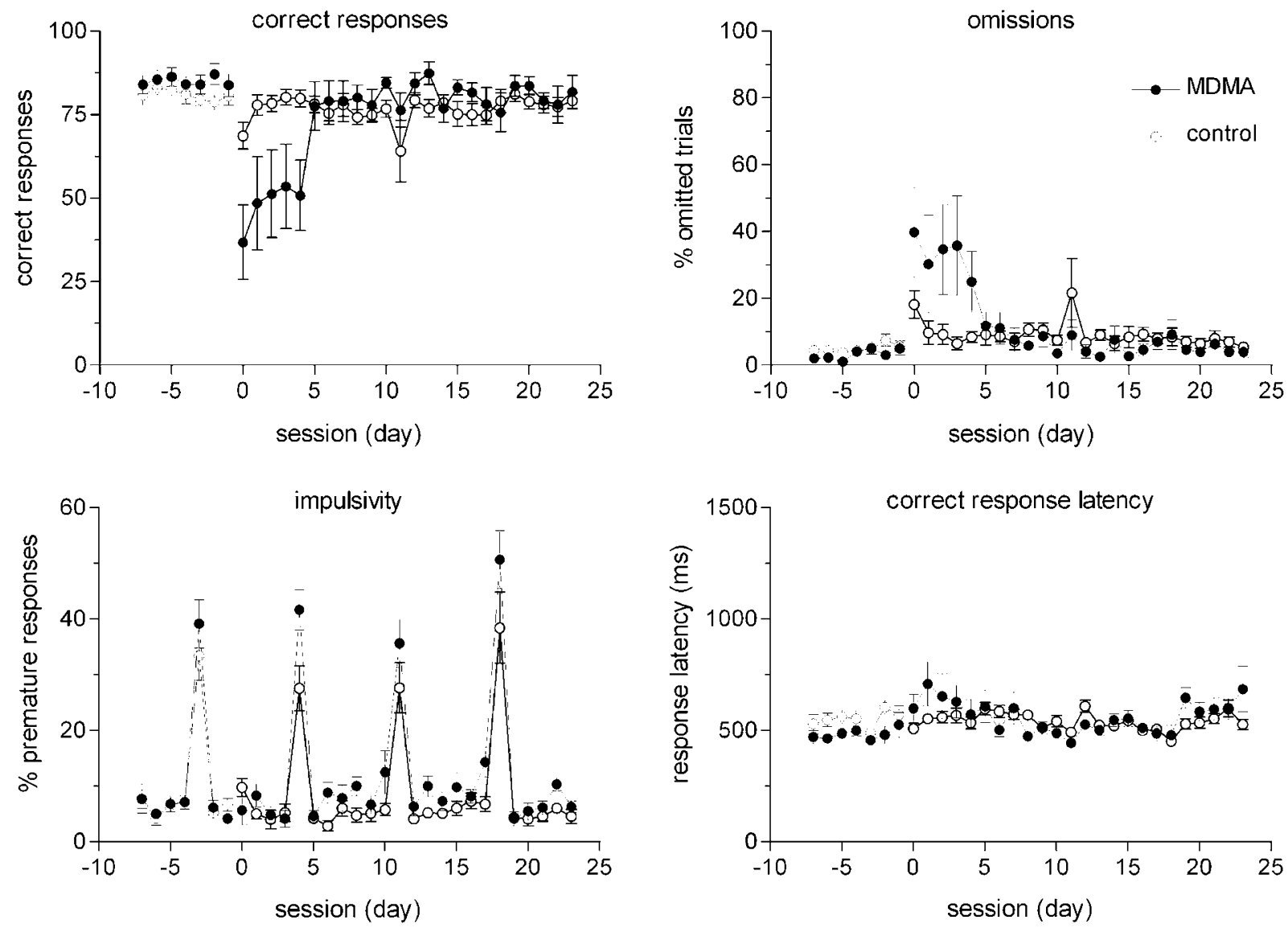

Figure 4 Effects of acute withdrawal of i.v. MDMA self-administration on attentional performance on the 5-CSRT task. Shown are mean ( \pm I SEM) correct responses, percentage omissions, percentage premature responses, and mean response latencies in active self-administering animals (closed symbols) and control subjects administered passive infusions of $0.9 \%$ saline (open symbols). Similar to MA, MDMA was also associated with significant elevations in impulsive responding that was evident approximately I week after withdrawal.
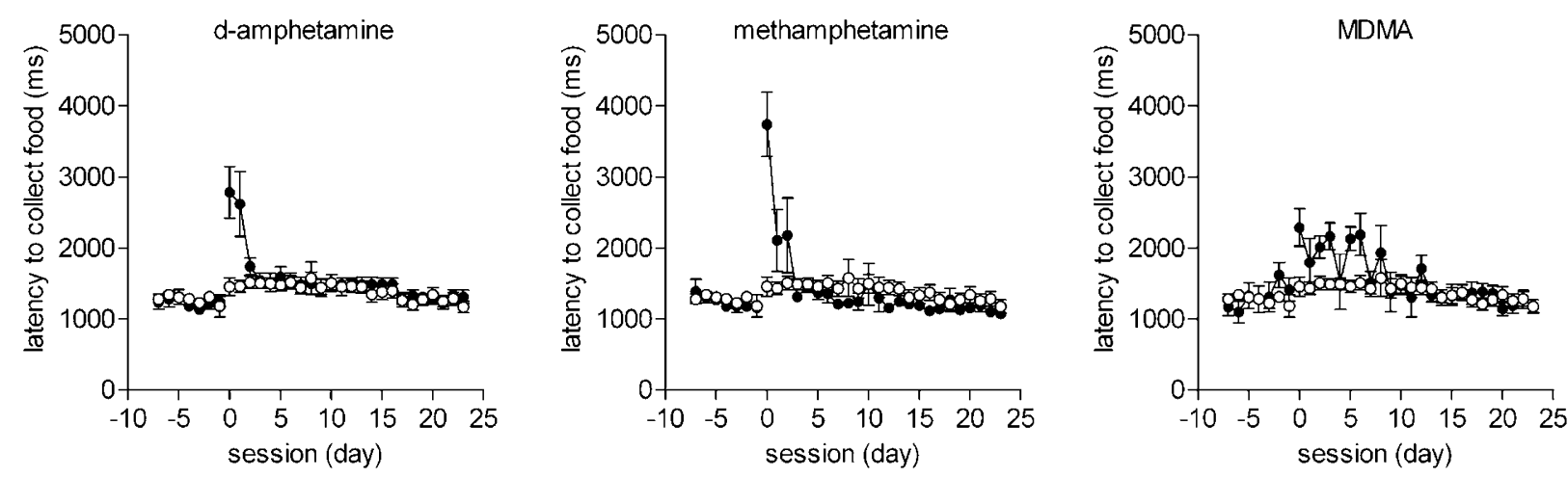

Figure 5 Effect of acute withdrawal of i.v. d-amphetamine, MA, and MDMA self-administration on magazine latencies on the 5-CSRT task. Shown are mean $( \pm$ I SEM) latencies (expressed in ms) in active self-administering animals (closed symbols) and control rats administered passive infusions of 0.9\% saline (open symbols).

heroin (see Dalley et al, 2005a,b). Finally, this study demonstrated the presence of residual deficits in rats withdrawn from MDMA self-administration for a period of 2 months, including a vigilance decrement, a reduction in impulsivity, increased omissions, and slower latencies to respond correctly and to collect food reward from the magazine. Deficits were also found in MA-exposed rats with residual effects mainly on motivational indices of performance under certain conditions. The discussion that follows considers the significance of the observed differences in the effects of withdrawal from i.v. $d$-amphetamine, MA, and MDMA self-administration and the relevance of the present behavioral findings to the cognitive and affective sequelae of chronic stimulant abuse in humans. 

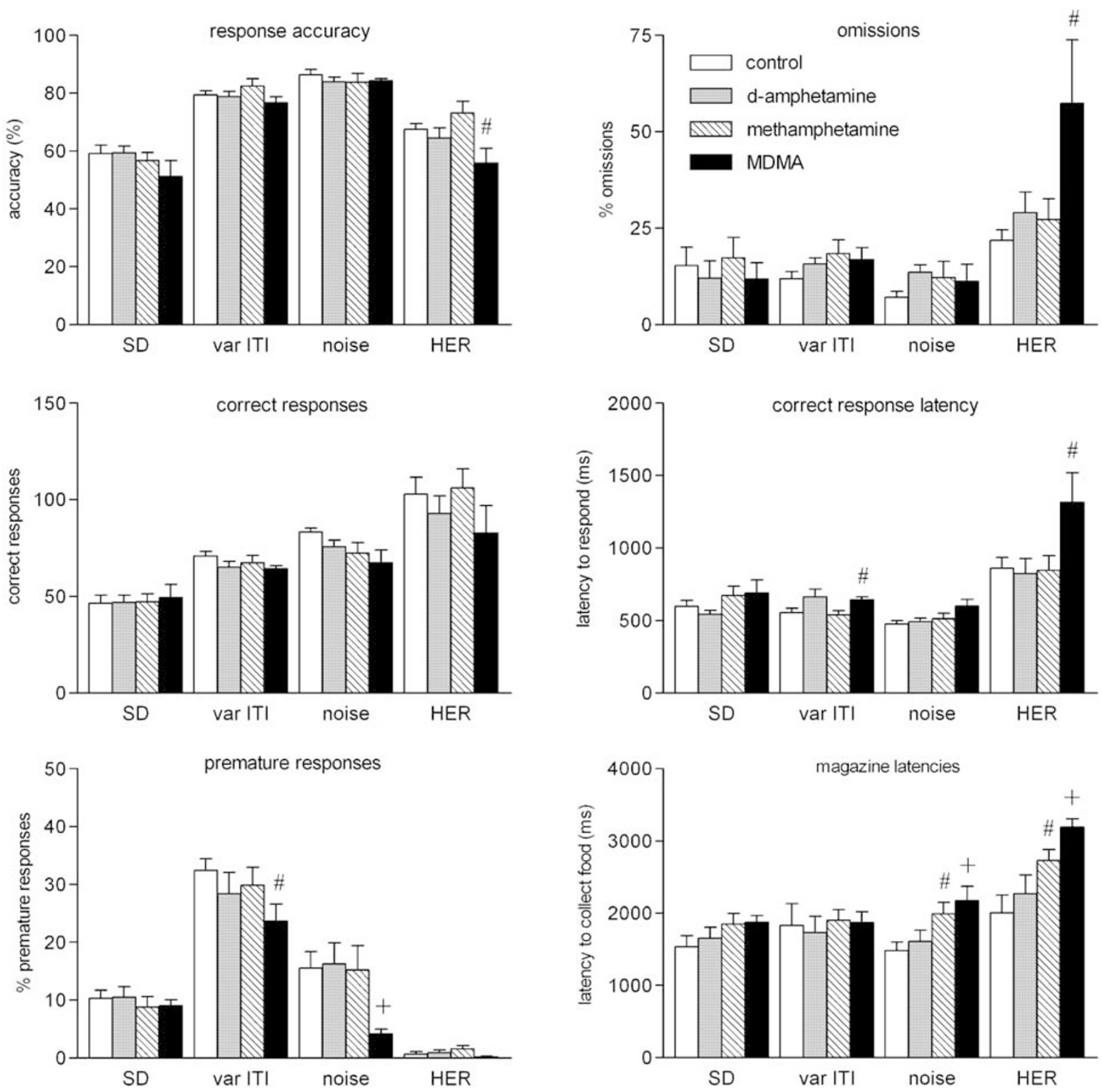

Figure 6 Residual psychomotor deficits in rats previously exposed to i.v. MDMA self-administration. Subjects were withdrawn for a 6-week period and subsequently tested under different challenge conditions, including a reduced stimulus duration ('SD') of $0.125 \mathrm{~s}$, a variable ITI ('var ITI'), white noise distractor ('noise'), and a high event rate ('HER'). Deficits in the accuracy and speed of correct responding as well as food collection latencies were most evident during the high event rate session where target stimuli were presented with high frequency over a large number of trials. ${ }^{\#} p<0.05 ;{ }^{+} p<0.0$ I (vs control group). Data are means \pm I SEM.

\section{Chronic Self-Administration of $d$-Amphetamine, MA, and MDMA}

A large corpus of data indicate that, following increased availability of opiate and stimulant drugs, rats typically show escalating rates of self-administration that normally develop within the first 7-10 days of drug exposure (Ahmed and Koob, 1999; Ahmed et al, 2000; Kitamura et al, 2006). It is unclear, therefore, why we were unable to demonstrate an escalation of MA self-administration, as seen in other studies in rats (Kitamura et al, 2006; Shepard et al, 2006). Although, in this study, sessions were limited both by time and by the number of infusions, it is unlikely that our results were affected by inadequate drug access because doses and session times were employed that were comparable to the above studies. Moreover, we did observe a progressive increase in $d$-amphetamine self-administration, similar to a previous study (Dalley et al, 2005a). This discrepancy suggests that variables in addition to drug availability may contribute to escalating rates of selfadministration (eg, rat strain). Nevertheless, it is clear that escalation per se is not an important determinant of cognitive outcome during the acute withdrawal period. Thus, of the three drugs tested, MA withdrawal was 
associated with the most severe behavioral deficits despite its lowered propensity to produce escalation in our hands.

A further finding meriting comment was the wide fluctuation in i.v. MDMA self-administration. Recent studies have shown that MDMA is self-administered by mice (Trigo et al, 2006), rats (Ratzenboeck et al, 2001; Cornish et al, 2003; Schenk et al, 2003), and monkeys (Fantegrossi et al, 2002, 2004), but supports lower rates of self-administration than cocaine (Ratzenboeck et al, 2001). Serotonergic mechanisms have been implicated in the reinforcing properties of MDMA, as MDMA self-administration is attenuated by 5-HT2 receptor antagonists such as ketanserin (Fantegrossi et al, 2002). MDMA also activates the DA system via inhibition of the DA transporter (Metzger et al, 1998) as well as indirectly via the activation of certain 5-HT receptor subtypes (eg, Schmidt et al, 1994). In a recent study, high rates of responding for MDMA were also reported during the initial phase of MDMA self-administration, which too decreased over subsequent exposure (Schenk et al, 2003). Here, it was speculated that the decrease in responding might reflect the long elimination half-life of MDMA and/or the accumulation of an active metabolite. However, influences such as these would likely affect the loading phase of MDMA self-administration and not the between-sessions rise and fall in MDMA selfadministration apparent in this study.

The initial rapid increase in MDMA self-administration in this study may be related to the emergence of tolerance, perhaps similar to that observed with serotonergic hallucinogens such as lysergic acid diethylamide (Winter, 1971) mediated by a downregulation in 5-HT2a receptor function (Gresch et al, 2005). As the reinforcing effects of MDMA depend, in part, on 5-HT2a receptor activity (Fantegrossi et al, 2002), putatively via increased DA release (Gobert and Millan, 1999; Yan et al, 2000), our present findings suggest that tolerance to the reinforcing effects of MDMA may be the result of diminished 5-HT2a receptor function. Thus, the sharp decline and subsequent lowering of responding for MDMA may reflect the inadequacy of 5-HT2a receptor function to support high rates of responding in the face of increasing tolerance. This may be relevant to reports that the subjective effects of ecstasy lessen with repeated use in humans (Beck and Rosenbaum, 1994) as well as to findings that spontaneous abstinence is high in adolescent and adult ecstasy users (von Sydow et al, 2002).

\section{Behavioral Consequences of $d$-Amphetamine, MA, and MDMA Self-Administration}

The main focus of this study was to elucidate whether longaccess, response-contingent administration of $d$-amphetamine and its analogs MA and MDMA results in long-term deficits in visuospatial attention and impulsivity. Previously, we found that withdrawal from 5-day cycles of i.v. $d$-amphetamine resulted in significant impairments in performance on the 5-CSRT task that persisted for up to 6 days (Dalley et al, 2005a). Surprisingly, although longer access to amphetamine in this study produced a more severe decline in performance, rats still recovered by the sixth day of withdrawal. Indeed, even when tested under more demanding conditions, rats previously exposed to amphetamine all showed a full recovery in attentional functioning. This would suggest that the neuronal plasticity that accompanies this history of chronic self-administration (see Robinson and Kolb, 2004) does not interfere permanently with executive functions of selection and inhibitory control. Thus, cognitive impairment in human amphetamine abusers may be limited to the acute withdrawal period only. However, it is important to point out that there are many forms of impulsivity (Evenden, 1999) and that the particular form of impulsivity measured in the 5-CSRT task may not necessarily be relevant to the forms of impulsivity underlying drug addiction. Clearly, additional studies will be needed to resolve this issue.

Chronic MA self-administration produced more disruptive effects on 5-CSRT performance during withdrawal than $d$-amphetamine, with deficits in baseline performance still evident 2 weeks after MA discontinuation. MA also produced residual effects on performance, specifically when an auditory distractor was presented and when the target stimuli were presented more frequently over many trials. In both cases, MA rats exhibited a selective increase in their latency to collect food reward from the magazine, a deficit perhaps suggestive of mild anhedonia (see Lin et al, 1999). As well as affecting general aspects of performance, similar to cocaine, heroin, and $d$-amphetamine (Dalley et al, 2005a,b), MA withdrawal also produced a short-lasting increase in impulsivity. Consistent with this finding, MA has been reported to increase other forms of impulsivity in rats, including choice for a large but delayed reward (Richards et al, 1999), a finding attributed by the authors to diminished DA transmission. It is unlikely though that a similar mechanism operated in this study, because reduced DA function is not normally associated with impulsiveness on the 5-CSRT task (Robbins, 2002). Clearly, further studies are needed to address this issue, including an investigation of altered 5-HT function.

Intriguingly, MDMA exposure led to a number of enduring deficits on the 5-CSRT task with a general slowing of responding and a reduced overall tendency to respond under certain conditions. MDMA-exposed rats were particularly sensitive to the high event rate manipulation, a test that probes the capacity of subjects to maintain attentional resources on a continuous basis. Notably, MDMA rats showed a decrement in attentional accuracy (or 'vigilance') and increased omissions and response latencies when the event rate was increased. They were also impaired when the target stimuli were made temporally unpredictable (variable ITI) and when distracting bursts of white noise were presented. The nature of these deficits implies that MDMA rats show lasting abnormalities in attentional functions related to selection, monitoring (eg, of readiness to respond) and maintenance. Interestingly, rather than showing increased impulsivity, as hypothesized to occur via MDMA-induced depletion of 5-HT, chronically withdrawn MDMA rats were actually less impulsive under certain conditions. A possible explanation is that the MDMA rats showed a general retardation in affective arousal (see below), evident by a slower overall speed of responding and increased omissions. Such effects may be different to those during the early stages of MDMA withdrawal where, like the MA group, impulsive responding on the 5-CSRT task increased significantly. The change from initially 
increased then to reduced impulsive responding in the MDMA group suggests dynamic neurochemical changes throughout the period of self-administration and withdrawal, which need to be characterized further.

\section{Implications for Cognitive Sequelae of Human Drug Abuse}

There is currently much controversy about the cognitive and mood-altering effects of stimulant drugs, including MDMA (Krystal et al, 1992; McKetin and Mattick, 1997; Bolla et al, 1998; Parrot et al, 1998; Gouzoulis-Mayfrank et al, 2000; Kalechstein et al, 2003; Nordahl et al, 2003; Thomasius et al, 2003; London et al, 2005). It is difficult, however, to be sure that long-term effects are necessarily limited to abuse of a particular drug in polydrug abusers, or to take into account confounding effects of comorbidity for other forms of psychiatric disorder (eg, see Sim et al, 2002). In this study, we have shown clear, persistent effects of MDMA withdrawal to impair attentional performance under challenge, and actually to reduce the vigor of behavioral output in terms of long-term reductions in impulsive responding (see also Montgomery et al, 2006), lengthening of magazine latency (to collect earned food pellets), and increased omissions. These data indicate persistent motivational and attentional impairments that may be relevant to reports of enhanced signs of depression in chronic MDMA users (Sumnall and Cole, 2005), in particular, in individuals carrying the short allele form of the 5-HT transporter (Roiser et al, 2006). Similar effects on magazine latency and reduction of impulsivity have been associated with changes in central 5-HT function in rats (Carli and Samanin, 1992; Dalley et al, 2002), although such behavior, as well as the control of attentional accuracy, is also affected by other monoaminergic and cholinergic systems (Robbins, 2002).

The findings are also be relevant to reports that human MA and MDMA abuse leads to cognitive impairment, especially on tests of verbal learning and memory, vigilance, and psychomotor speed (McKetin and Mattick, 1997; Bolla et al, 1998; Parrot et al, 1998; Gouzoulis-Mayfrank et al, 2000; Kalechstein et al, 2003; Nordahl et al, 2003; London et al, 2005), and to a recent report that abstinent MA abusers are impaired on an analogous rapid visual information processing task, which too assesses attentional function and distractibility (Johanson et al, 2006). Importantly, this study shows that related cognitive disturbances can be demonstrated in animals with a controlled history of MA and MDMA intake. The findings thus raise concerns about the frequent use of MA and especially ecstasy in otherwise normal healthy individuals.

\section{ACKNOWLEDGEMENTS}

This research was supported by a consortium joint award from the UK Medical Research Council (MRC), and Wellcome Trust within the University of Cambridge Behavioural and Clinical Neuroscience Institute (BCNI), and by an MRC Pathfinder award to JWD, BJE and TWR (G0401068). YP was supported by a predoctoral FI scholarship from Generalitat de Catalunya.

\section{REFERENCES}

Ahmed SH, Koob GF (1999). Long-lasting increase in the set point for cocaine self-administration after escalation in rats. Psychopharmacology 146: 303-312.

Ahmed SH, Walker JR, Koob GF (2000). Persistent increase in the motivation to take heroin in rats with a history of drug escalation. Neuropsychopharmacology 22: 413-421.

Beck J, Rosenbaum M (1994). Pursuit of Ecstasy: The MDMA Experience. State University of New York Press: Albany.

Bolla KI, McCann UD, Ricaurte GA (1998). Memory impairment in abstinent MDMA ('Ecstasy') users. Neurology 51: 1532-1537.

Caine SB, Lintz R, Koob GF (1992). Intravenous drug selfadministration techniques in animals. In: Sahgal A (ed). Behavioral Neuroscience, A Practical Approach, Vol 1. Oxford University Press: Oxford. pp 117-143.

Cardinal RN, Aitken MRF (2001). Whisker, version 2.2, computer software. http://www.whisker.control.com.

Carli M, Samanin R (1992). Serotonin2 receptor agonists and serotonergic anorectic drugs affect rats' performance differently in a five-choice serial reaction time task. Psychopharmacology 106: $228-234$.

Chudasama Y, Passetti F, Desai A, Rhodes S, Lopian D, Robbins TW (2003). Dissociable aspects of performance on the 5-choice serial reaction time task following lesions of the dorsal anterior cingulate, infralimbic and orbitofrontal cortex in the rat: differential effects on selectivity, impulsivity and compulsivity. Behav Brain Res 146: 105-119.

Cornish JL, Shahnawaz Z, Thompson MR, Wong S, Morley KC, Hunt GE et al (2003). Heat increases 3,4-methylenedioxymethamphetamine self-administration and social effects in rats. Eur J Pharmacol 482: 339-341.

Dalley JW, Theobald DE, Eagle DM, Passetti F, Robbins TW (2002). Deficits in impulse control associated with tonically-elevated serotonergic function in rat prefrontal cortex. Neuropsychopharmacology 26: 716-728.

Dalley JW, Theobald DE, Berry D, Milstein J, Lääne K, Everitt BJ et al (2005a). Cognitive sequelae of intravenous amphetamine self-administration in rats: evidence for selective effects on attentional performance. Neuropsychopharmacology 30: 525-537.

Dalley JW, Lääne K, Pena Y, Theobald DE, Everitt BJ, Robbins TW (2005b). Attention and motivational deficits in rats withdrawn from intravenous self-administration of cocaine or heroin. Psychopharmacology 182: 579-587.

Ernst T, Chang L, Leonido-Yee M, Speck O (2000). Evidence for long-term neurotoxicity associated with methamphetamine abuse: a 1H MRS study. Neurology 54: 1344-1349.

Evenden JL (1999). Impulsivity: a discussion of clinical and experimental findings. J Psychopharmacol 137: 410-414.

Fantegrossi WE, Ullrich T, Rice KC, Woods JH, Winger G (2002). 3,4-Methylenedioxymethamphetamine (MDMA, 'ecstasy') and its stereoisomers as reinforcers in rhesus monkeys: serotonergic involvement. Psychopharmacology 161: 356-364.

Fantegrossi WE, Woolverton WL, Kilbourn M, Sherman P, Yuan J, Hatzidimitriou G et al (2004). Behavioral and neurochemical consequences of long-term intravenous self-administration of MDMA and its enantiomers by rhesus monkeys. Neuropsychopharmacology 29: 1270-1281.

Gobert A, Millan MJ (1999). Serotonin (5-HT)2A receptor activation enhances dialysate levels of dopamine and noradrenaline, but not 5-HT, in the frontal cortex of freely-moving rats. Neuropharmacology 38: 315-317.

Gouzoulis-Mayfrank E, Daumann J, Tuchtenhagen F, Pelz S, Becker S, Kunert HJ et al (2000). Impaired cognitive performance in drug free users of recreational ecstasy (MDMA). J Neurol Neurosurg Psychiatry 68: 719-725.

Gresch PJ, Smith RL, Barrett RJ, Sanders-Bush E (2005). Behavioral tolerance to lysergic acid diethylamide is associated with 
reduced serotonin-2A receptor signaling in rat cortex. Neuropsychopharmacology 30: 1693-1702.

Harrison AA, Everitt BJ, Robbins TW (1999). Central 5-HT depletion enhances impulsive responding without affecting the accuracy of attentional performance: interactions with dopaminergic mechanisms. Psychopharmacology 133: 329-342.

Harvey DC, Lcan G, Tanious SP, Melega WP (2000). Recovery from methamphetamine induced long-term nigrostriatal dopaminergic deficits without substantia nigra cell loss. Brain Res 871: 259-270.

Hester R, Garavan H (2004). Executive dysfunction in cocaine addiction: evidence for discordant frontal, cingulate, and cerebellar activity. J Neurosci 24: 11017-11022.

Jentsch JD, Taylor JR (1999). Impulsivity resulting from frontostriatal dysfunction in drug abuse: implications for the control of behavior by reward-related stimuli. Psychopharmacology 146: 373-390.

Johanson C-E, Frey KA, Lundahl LH, Keenan P, Lockhart N, Roll J et al (2006). Cognitive function and nigrostriatal markers in abstinent methamphetamine abusers. Psychopharmacology 185: 327-338.

Kalechstein AD, Newton TF, Green M (2003). Methamphetamine dependence is associated with neurocognitive impairment in the initial phases of abstinence. J Neuropsychiatry Clin Neurosci 15: 215-220.

Keppel G (1991). Design and Analysis. Prentice-Hall: Englewood Cliffs, NJ.

Khantzian EJ (1985). The self-medication hypothesis of addictive disorders: focus on heroin and cocaine dependence. Am J Psychiatry 142: 1259-1264.

Kitamura O, Wee S, Specio SE, Koob GF, Pulvirenti L (2006). Escalation of methamphetamine self-administration in rats: a dose-effect function. Psychopharmacology 186: 48-53.

Krystal JH, Price LH, Opsahl C, Ricaurte GA, Heninger GR (1992). Chronic 3,4-methylenedioxymethamphetamine (MDMA) use: effects on mood and neuropsychological function. Am J Drug Alcohol Abuse 18: 331-341.

Levin FR, Kleber HD (1995). Attention-deficit hyperactivity disorder and substance abuse: relationships and implications for treatment. Harv Rev Psychiatry 2: 246-258.

Lin D, Koob GF, Markou A (1999). Differential effects of withdrawal from chronic amphetamine or fluoxetine administration on brain stimulation reward in the ratinteractions between the two drugs. Psychopharmacology 145: 283-294.

London ED, Berman SM, Voytek B, Simon SL, Mandelkern MA, Monterosso J et al (2005). Cerebral metabolic dysfunction and impaired vigilance in recently abstinent methamphetamine abusers. Biol Psychiatry 58: 770-778.

Lorez H (1981). Fluorescence histochemistry indicates damage of striatal dopamine nerve terminals in rats after multiple doses of methamphetamine. Life Sci 28: 911-916.

McCann UD, Ricaurte GA (2004). Amphetamine neurotoxicity: accomplishments and remaining challenges. Neurosci Biobehav Rev 27: 821-826.

McCann UD, Szabo Z, Scheffel U, Dannals RF, Ricaurte GA (1998a). Positron emission tomographic evidence of toxic effect of MDMA ('ecstasy') on brain serotonin in human beings. Lancet 352: 1433-1437.

McCann UD, Wong DF, Yokoi F, Villemagne V, Dannals RF, Ricaurte GA (1998b). Reduced striatal dopamine transporter density in abstinent methamphetamine and methcathinone users: evidence from positron emission tomography studies with [ $\left.{ }^{11} \mathrm{C}\right]$ WIN-35,428. J Neurosci 18: 8417-8422.

McKetin R, Mattick RP (1997). Attention and memory in illicit amphetamine users. Drug Alcohol Depend 48: 235-242.

Melega WP, Raleigh MJ, Stout DB, Lacan G, Huang SC, Phelps ME (1997). Recovery of striatal dopamine function after acute amphetamine and methamphetamine-induced neurotoxicity in the vervet monkey. Brain Res 766: 113-120.

Metzger RR, Hanson GR, Gibb JW, Fleckenstein AE (1998). 3,4-Methylenedioxymethamphetamine-induced acute changes in dopamine transporter function. Eur J Pharmacol 349: 205-210.

Montgomery C, Fisk JE, Newcombe R, Murphy PN (2006). The differential effects of ecstasy/polydrug use on executive components: shifting, inhibition, updating and access to semantic memory. Psychopharmacology 182: 262-276.

Nordahl TE, Salo R, Leamon M (2003). Neuropsychological effects of chronic methamphetamine use on neurotransmitters and cognition: a review. J Neuropsychiatry Clin Neurosci 15: 317-325.

Parrot AC, Lees A, Garnham NJ, Jones M, Wesnes K (1998). Cognitive performance in recreational users of MDMA or ecstasy. J Psychopharmacology 12: 79-83.

Ratzenboeck E, Saria A, Kriechbaum N, Zernig G (2001). Reinforcing effects of MDMA ('Ecstasy') in drug-naïve and cocaine-trained rats. Pharmacology 62: 138-144.

Ricaurte GA, Martello AL, Katz JL, Martello MB (1992). Lasting effects of (+/-)-3,4-methylenedioxymethamphetamine (MDMA) on central serotonergic neurons in nonhuman primates: neurochemicral observations. J Pharmacol Exp Ther 261: 616-622.

Richards JB, Sabol K, de Wit H (1999). Effects of methamphetamine on the adjusting amount procedure, a model of impulsive behavior in rats. Psychopharmacology 146: 432-439.

Robbins TW (2002). The 5-choice serial reaction time task: behavioral pharmacology and functional neurochemistry. Psychopharmacology 163: 363-380.

Robinson TE, Kolb B (2004). Structural plasticity associated with exposure to drugs of abuse. Neuropharmacology 47: 33-46.

Roiser JP, Blackwell AD, Cools R, Clark L, Rubinsztein DC, Robbins TW et al (2006). Serotonin transporter polymorphism mediates vulnerability to loss of incentive motivation following acute tryptophan depletion. Neuropsychopharmacology 31: 2264-2272.

Schenk S, Gittings D, Johnstone M, Daniela E (2003). Development, maintenance and temporal pattern of self-administration maintained by ecstasy (MDMA) in rats. Psychopharmacology 169: 21-27.

Shepard JD, Chuang DT, Shaham Y, Morales M (2006). Effect of methamphetamine self-administration on tyrosine hydroxylase and dopamine transporter levels in mesolimbic and nigrostriatal dopamine pathways in the rat. Psychopharmacology 185: 505-513.

Seiden LS, Fischman MW, Schuster CR (1976). Long-term methamphetamine induced changes in brain catecholamines in tolerant rhesus monkeys. Drug Alcohol Depend 1: 215-219.

Segal DS, Kuczenski R, O’Neil ML, Melega WP, Cho AK (2005). Prolonged exposure of rats to intravenous methamphetamine: behavioral and neurochemical characterisation. Psychopharmacology 180: 501-512.

Semple DM, Ebmeier KP, Glabus MF, O'Carroll RE, Johnstone EC (1999). Reduced in vivo binding to the serotonin transporter in the cerebral cortex of MDMA ('ecstasy') users. Br J Psychiatry 175: 63-69.

Sim T, Simon SL, Domier CP, Richardson K, Rawson RA, Ling W (2002). Cognitive deficits among methamphetamine users with attention deficit hyperactivity disorder symptomatology. J Addict Dis 21: 75-89.

Simon SL, Domier CP, Carnell J, Brethen P, Rawson R, Ling W (2000). Cognitive impairment in individuals currently using methamphetamine. Am J Addict 9: 222-231.

Schmidt CJ, Sullivan CK, Fadayel GN (1994). Blockade of striatal 5 -HT2 receptors reduced the increase in extracellular concentrations of dopamine produced by the amphetamine analogue 3,4methylenedioxymethamphetamine. J Neurochem 62: 1382-1389.

Stefanski R, Lee S-H, Yasar S, Cadet JL, Goldberg SR (2002). Lack of persistent changes in the dopaminergic system of rats 
withdrawn from methamphetamine self-administration. Eur J Pharmacol 439: 59-68.

Sumnall HR, Cole JC (2005). Self-reported depressive symptomatology in community samples of polysubstance misusers who report Ecstasy use: a meta-analysis. J Psychopharmacol 19: 84-92.

Thomasius R, Petersen K, Buchert R, Andersen B, Zapletalova P, Wartberg L et al (2003). Mood, cognition and serotonin transporter availability in current and former ecstasy (MDMA) users. Psychopharmacology 167: 85-96.

Thompson PM, Hayashi KM, Simon SL, Geaga JA, Hong MS, Sui Y et al (2004). Structural abnormalities in the brains of human subjects who use methamphetamine. J Neurosci 24: 6028-6036.

Trigo JM, Panayi F, Soria G, Maldonado R, Robledo P (2006). A reliable model of intravenous MDMA self-administration in naive rats. Psychopharmacology 184: 212-220.

Volkow ND, Chang L, Wang GJ, Fowler JS, Franceschi D, Sedler M et al (2001). Loss of dopamine transporters in methamphetamine abusers recovers with protracted abstinence. J Neurosci 21: 9414-9418.

Volkow ND, Fowler JS, Wang G-J, Hitzemann R, Logan J, Schlyer DJ et al (1993). Decreased dopamine D2 receptor availability is associated with reduced frontal metabolism in cocaine abusers. Synapse 14: 169-177.

Von Sydow K, Lieb R, Pfister H, Hofler M, Wittchen HU (2002). Use, abuse and dependence of ecstasy and related drugs in adolescents and young adults - a transient phenomenon? Results from a longitudinal community study. Drug Alcohol Depend 66: 147-159.

Wang GJ, Volkow ND, Chang L, Miller E, Sedler M, Hitzemann R et al (2004). Partial recovery of brain metabolism in methamphetamine abusers after protracted abstinence. Am J Psychiatry 161: $242-248$.

Wilson JM, Kalasinsky KS, Levey AI, Bergeron C, Reiber G, Anthony RM et al (1996). Striatal dopamine nerve terminal markers in human, chronic methamphetamine users. Nat Neurosci 2: 699-703.

Winstanley CA, Dalley JW, Theobald DE, Robbins TW (2004). Fractionating impulsivity: contrasting effects of central 5-HT depletion on different measures of impulsive behavior. Neuropsychopharmacology 29: 1331-1343.

Winter JC (1971). Tolerance to the behavioral effect of lysergic acid diethylamide and cross-tolerance to mescaline in the rat: absence of a metabolic component. J Pharmacol Exp Ther 178: 625-630.

Woolverton WL, Ricaurte GA, Forno LS, Seiden LS (1989). Longterm effects of chronic methamphetamine administration in rhesus monkeys. Brain Res 486: 73-78.

Yan Q, Reith ME, Yan S (2000). Enhanced accumbal dopamine release following 5-HT(2A) receptor stimulation in rats pretreated with intermittent cocaine. Brain Res 863: 254-258. 